\title{
BMJ Open Different doses of prucalopride in treating chronic idiopathic constipation: a meta-analysis and Bayesian analysis
}

\author{
Tao Yang (D) , ${ }^{1}$ Kaili Wang, ${ }^{2}$ Yibo Cao, ${ }^{3}$ Jianxia Wen, ${ }^{4}$ Shizhang Wei, ${ }^{5}$ Haotian $\mathrm{Li},{ }^{5}$ \\ Xiangdong Yang, ${ }^{6}$ Tianbao $\mathrm{Xiao}^{7}$
}

To cite: Yang T, Wang $\mathrm{K}$, Cao Y, et al. Different doses of prucalopride in treating chronic idiopathic constipation: a meta-analysis and Bayesian analysis. BMJ Open 2021;11:e039461. doi:10.1136/ bmjopen-2020-039461

- Prepublication history for this paper is available online. To view these files, please visit the journal online (http://dx.doi. org/10.1136/bmjopen-2020039461).

SW and HL contributed equally.

Received 17 April 2020

Revised 19 January 2021

Accepted 31 January 2021
Check for updates

(C) Author(s) (or their employer(s)) 2021. Re-use permitted under CC BY-NC. No commercial re-use. See rights and permissions. Published by BMJ.

For numbered affiliations see end of article.

Correspondence to Professor Tianbao Xiao; prof_xiaotianbao@163.com

\section{ABSTRACT}

Objective This study aims to explore the incremental benefit of different doses of prucalopride in treating chronic idiopathic constipation (CIC).

Methods PubMed, EMBASE, MEDLINE, Cochrane Library, Chinese Biomedical Database, China National Knowledge Infrastructure, VIP medicine information and Wanfang databases were comprehensively searched up to March 2020. Prospective trials with different doses of prucalopride versus placebo were selected. The frequency of spontaneous bowel movements (SBMs) per week and the treatment-emergent adverse events (TEAEs), such as headache, arrhythmia, diarrhoea, dizziness, nausea and vomiting, were first synthesised in a meta-analysis. The probability of optimal dose of prucalopride was then ranked by random-effects within Bayesian analysis. Results 14 high-quality randomised controlled trials with 4328 patients were ultimately included. SBMs per week increased significantly after using $1 \mathrm{mg}$ (OR: $2.40,95 \%$ Cl 1.32 to 4.37$), 2 \mathrm{mg}$ (OR: $2.55,95 \% \mathrm{Cl} 1.93$ to 3.36$)$ and $4 \mathrm{mg}$ (OR: 2.51, 95\% Cl 1.92 to 3.28) prucalopride. Bayesian analysis demonstrated $1 \mathrm{mg}$ dose obtained the maximum SBMs per week (OR: $3.31,95 \%$ credible interval 1.72 to 6.16 , probability rank=0.70) indirectly compared with $2 \mathrm{mg}$ and $4 \mathrm{mg}$ doses. TEAEs were higher significantly in $2 \mathrm{mg}$ (risk ratio (RR): $1.20,95 \% \mathrm{Cl} 1.09$ to 1.33 ) and $4 \mathrm{mg}$ (RR: $1.14,95 \% \mathrm{Cl} 1.07$ to 1.22 ) prucalopride. The $1 \mathrm{mg}$ dose did not reach statistical significance (RR: 1.17, $95 \% \mathrm{Cl} 0.94$ to 1.44).

Conclusions The study concludes that $1 \mathrm{mg}$ dose at commencement could be safer in treating $\mathrm{CIC}$ and that $2 \mathrm{mg}$ prucalopride could be more efficacious in terms of SBMs per week outcome receiving.

PROSPERO registration number CRD42019136679.

\section{INTRODUCTION}

One of the most complicated disorders of the digestive system is chronic idiopathic constipation (CIC). The global prevalence of CIC in adults was estimated at $14 \%$ (95\% CI $12 \%$ to $17 \%) .^{1}$ Age, particularly over 65 years, and female gender could be potential risk factors for increased prevalence. ${ }^{2}$ CIC has the ability to curtail quality of life and increase psychological distress significantly. ${ }^{3}$ Furthermore, these harmful effects are inclined to be more widespread in patients with inability to

\section{Strengths and limitations of this study}

- This study applied comprehensive analysis methods, including meta-analysis, meta regression and Bayesian network analysis.

- This study confirms that there is no incremental benefit in prucalopride application and that $1 \mathrm{mg}$ dose could be safer in treating chronic idiopathic constipation.

- Intention-to-treat analysis missing in many original studies may result in assessment bias.

- Undetected bias and methodological limitations could de-escalate the robustness of our results.

- The total number of patients in each dose group is small and this could contribute to an uncertain and controversial conclusion.

coordinate bowel movements than in patients with constipation with slow transition. ${ }^{4} \mathrm{~A}$ community survey about spending in CIC management demonstrates this annoying disease enormously increases social and economic burden. ${ }^{56}$

Management methods are also hard and arduous strikingly for both gastrointestinal doctors and surgeons worldwide. Although laxatives (both stimulant and osmotic) have been widely employed in clinical practice, evidence on long-term efficacy in clinical setting remains inadequate. ${ }^{7}$ Furthermore, the weakened gastrointestinal motility and impairment of the intestinal nervous system (INS) precipitate the occurrence of CIC evidently. ${ }^{8}$ Therefore plausible treatments for CIC are suggested to focus on the neurons in the INS and improve their physiological excitability. ${ }^{9}$ Although many novel pharmacological attempts have been made, such as cisapride, tegaserod and lubiprostone, 'these attempts failed to earn popularity among clinical physicians and surgeons and failed to be included as first-line treatments, possibly due to remarkable side effects, possibly due to remarkable side effects (eg, cardiovascular 
problems). Prucalopride was then investigated in clinical trials.

Prucalopride, a highly selective serotonin 5-hydroxytryptamine 4 (5-HT4) agonist, was introduced to the market in 2009. The pharmacological mechanism of prucalopride is to stimulate the receptors of 5-HT4, which are diffusely concentrated on the enteric neurons. The excitatory neurotransmitter acetylcholine is then released by the 5-HT4 agonists and promotes mucosal secretion. ${ }^{10}$ Prucalopride has been advocated by the US Food and Drug Administration and the European Union for symptomatic treatment of CIC, especially in patients who have failed to adequately achieve symptom relief following stimulant or osmotic laxatives. ${ }^{11}$ Previous randomised controlled trials (RCTs) have reported prucalopride doses of $0.5 \mathrm{mg}, 1 \mathrm{mg}, 2 \mathrm{mg}$ and $4 \mathrm{mg}$ compared with placebo accelerated colonic transit and spontaneous bowel movements (SBMs) per week prominently. ${ }^{12-15}$ However, there are rare guidelines or expert opinions to explore the incremental benefit of prucalopride. The administration of doses in clinical practice is empirical in most cases. ${ }^{16}$ It remains a conundrum whether dosedependent relationship exists in using prucalopride.

This article attempts to define the clinical usefulness and safety of different doses of prucalopride in treating patients with CIC. We intend to provide the optimal dose of prucalopride for gastrointestinal physicians in clinical work and employed both pairwise meta-analysis and Bayesian analysis to address these problems as much as possible.

\section{MATERIALS AND METHODS}

Patient and public involvement

No patients were involved.

\section{Protocol registration}

We have registered this protocol in PROSPERO (International Prospective Register of Systematic Reviews) in May 2019 (https://www.crd.york.ac.uk/PROSPERO).

\section{Eligibility criteria}

The Cochrane Handbook for Systematic Reviews of Interventions and the Preferred Reporting Items for Systematic Reviews and Meta-Analyses statement ${ }^{17}$ were used in this study. Studies that meet the following inclusion criteria were included: (1) the design of the study was a prospectively randomised controlled trial; (2) CIC was histologically confirmed; and (3) at least one of the investigated outcomes were reported in the original research. Exclusion criteria were as follows: (1) irrelevant studies and duplicate literature; (2) unavailable data in the literature; and (3) letters, reviews, comments, case reports and meta-analyses.

\section{Search methodology}

PubMed, EMBASE, MEDLINE, Cochrane Library, Chinese Biomedical Database, China National Knowledge
Infrastructure, VIP medicine information system and Wanfang electronic databases were comprehensively searched up to March 2020. The search terms were a combination of medical subject headings $(\mathrm{MeSH})$ terms and the following free words: (constipation/chronic constipation/functional constipation) and (prucalopride/Resolor) and (random/randomized/RCTs/clinical trial). In addition, we manually searched for other potential and relevant references. There were no limitations in the language of all publications. Taking the PubMed database as an example, the search strategies are as follows:

- \#1 constipation (MeSH).

- \#2 constipation* af.

- \#3 chronic constipation af.

- \#4 functional constipation af.

- \#5 \#1 OR \#2 OR \#3 OR \#4.

- \#6 prucalopride (MeSH).

- \#7 prucalopride af.

- \#8 Resolor af.

- \#9 \#6 OR \#7 OR \#8.

- \#10 \#5 AND \#9.

- \#11 random*af.

- \#12 \#10 AND \#11.

\section{Study selection}

Two investigators (TY and LKW) filtered the original studies independently. If the literature meets the eligibility criteria, the two investigators will further read the full text to screen the study. Any discrepancies were addressed by discussion or third party consensus.

\section{Data extraction and analysis}

All data were collected independently by two investigators (TY and BYC) from eligible RCTs using a standardised form. The following information was extracted: (1) study identification, including author name and publication year; (2) country where the study was conducted; (3) study subjects, number of participants and male to female ratio; (4) settings of trial arms and specific dose of prucalopride; (5) the primary outcome was SBMs per week, while the secondary outcome was treatment-emergent adverse events (TEAEs), defined as the total complications following prucalopride application, including headache, diarrhoea, dizziness, nausea, vomiting and so on, and were collectively reported in original trials and diagnosed using the same criteria. If insufficient details were reported, the authors were contacted for further information. Disagreements between two investigators were addressed by discussion and consensus.

\section{Quality assessment}

The Cochrane Collaboration's tool for assessing risk of bias and the Jadad scoring system ${ }^{18}$ were employed for quality evaluation. Randomisation, double blinding and dropout/withdrawal management were the main components of the Jadad scale. Any disagreements during 
assessment were resolved by iteration, discussion and consensus.

\section{Statistical analysis}

Traditional pairwise meta-analysis with STATA

All original data were performed using STATA V.13.0 software for Windows. $Q$ test and $I^{2}$ test were used to evaluate heterogeneity before pooled effects. The fixed-effect and random-effect models were based on the result of $Q$ test and $I^{2}$ test. A fixed-effect model was adopted if $I^{2}$ was $<50 \%$ and $p>0.1$. Otherwise, a random-effect model was chosen. For the outcomes, the proportion of patients reaching SBMs per week was set as the dichotomous variable, and the pooled analysis of SBMs was expressed as unadjusted OR. The TEAE was also a dichotomous variable, and we intend to apply risk ratio (RR) for synthesised effect. The 95\% CI was calculated simultaneously within pooled OR and RR. Possible sources of heterogeneity were explored by meta-regression performed via a fixed-effect model; the the restricted maximum likelihood (REML) estimation method proposed by Harbord et $a l^{19}$ was applied in meta-regression. Sensitivity analysis was carried out by omitting each trial one by one. Possible publication bias was determined by Egger's regression asymmetry test. ${ }^{20}$ Meanwhile, contour-enhanced funnel plot was applied to distinguish detailed reasons for publication bias. ${ }^{21}$

\section{Optimal dose of prucalopride ranked by Bayesian analysis}

Bayesian framework provided a multiple-treatment metaanalysis model because it allows a feasible and practical estimation of direct and indirect comparisons based on probabilities, ranks or predictions. ${ }^{22}{ }^{23}$ In the current study, different doses of prucalopride $(1 \mathrm{mg}, 2 \mathrm{mg}$ and $4 \mathrm{mg}$ ) and placebo were set as individual treatment groups. A random-effects approach was applied within a Bayesian framework with the GeMTC package in R (V.3.6.0). The Markov chain Monte Carlo method was used for pooled estimates. To achieve posterior distribution, three independent Markov chains were run simultaneously. Running for 20000 adaptations and 100000 updates per chain, the updating frequency of chain per one update was set as 10. Running lengths were extended if the Markov chains had not converged. ${ }^{24}$ Probabilities of being superior were obtained from the posterior distribution. Ranks were obtained according to the estimated OR and RR. After posterior distributions were ensured, 95\% credible interval (CrI) was derived from the 2.5th and 97.5 th percentiles. The probability of the optimal dose of prucalopride was ranked using the surface under the cumulative ranking (SUCRA), which ranges between $0 \%$ and $100 \% .^{22}$ A parameter to rank different doses of prucalopride based on their probability of ranking first, second or third was used.

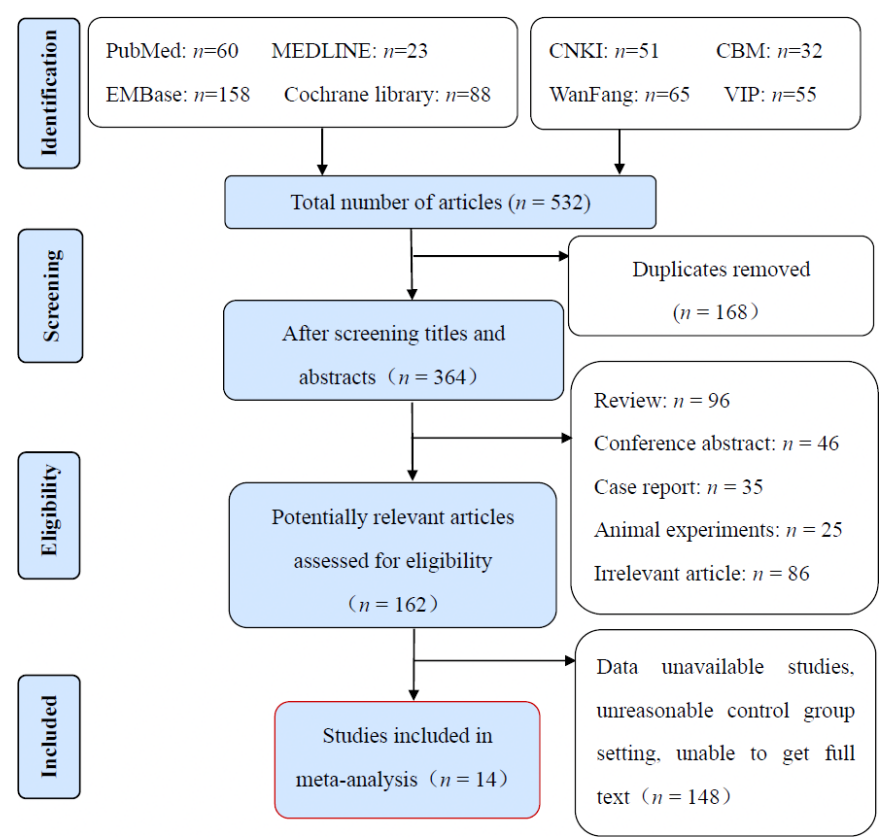

Figure 1 Flow chart presenting the selection process of studies, according to the PRISMA guidelines. CBM, Chinese Biomedical Database; CNKI, China National Knowledge Infrastructure; PRISMA, Preferred Reporting Items for Systematic Reviews and Meta-Analyses.

\section{RESULTS}

\section{Study selection outcome}

There were 532 relevant articles retrieved ultimately, among which 168 were duplicate articles. In total, 202 studies were excluded by title and abstract screening due to the studies being reviews, conference abstracts, animal experiments and case reports; this resulted in 162 articles. After examining the abstracts and full texts, 148 articles were further excluded. The meta-analysis finally included 14 studies $^{13-15}$ 25-35 that fulfilled the inclusion criteria (figure 1).

\section{Study characteristics}

In total, 4328 patients were included in the 14 studies. ${ }^{13-15} 25-35$ The mean sample size was 309 participants, ranging between $37^{27}$ and $713^{15}$ patients. Table 1 displays the main characteristics of the 14 studies. Overall, 14 studies were published between 2001 and 2015 years, and 12 studies ${ }^{13-15}$ 25-30 33-35 were conducted in Western countries and 2 in Asian countries. ${ }^{31}{ }^{32}$ With respect to the treatment protocols, seven trials ${ }^{262831-35}$ had one-arm design, five trials ${ }^{1315252730}$ had two-arm setting, and two trials $^{1429}$ had three-arm design. One trial ${ }^{29}$ used $0.5 \mathrm{mg}$ prucalopride (PRU) versus placebo, $1 \mathrm{mg}$ prucalopride was applied in 4 trials, ${ }^{14} 26272912$ trials $^{13-15} 252729-35$ employed $2 \mathrm{mg}$ prucalopride versus placebo, and 6 trials $^{13-15} 252830$ made use of $4 \mathrm{mg}$ prucalopride versus placebo. There were diverse durations, ranging from 1 to 24 weeks. To retrieve data and combine outcomes consistently, our study analysed SBMs per week and total TEAEs after using $1 \mathrm{mg}, 2 \mathrm{mg}$ and $4 \mathrm{mg}$ doses of prucalopride. 
Table 1 Main information of the studies included in the meta-analysis

\begin{tabular}{|c|c|c|c|c|c|c|c|c|}
\hline \multirow{2}{*}{$\begin{array}{l}\text { Study } \\
\text { identification }\end{array}$} & \multirow{2}{*}{$\begin{array}{l}\text { Publication } \\
\text { year }\end{array}$} & \multirow[b]{2}{*}{ Region } & \multirow{2}{*}{$\begin{array}{l}\text { Total } \\
\text { patients (n) }\end{array}$} & \multicolumn{2}{|c|}{$M / F(n)$} & \multirow{2}{*}{$\begin{array}{l}\text { Treatment } \\
\text { protocols }\end{array}$} & \multirow{2}{*}{$\begin{array}{l}\text { Treatment } \\
\text { duration } \\
\text { (weeks) }\end{array}$} & \multirow[b]{2}{*}{ Clinical endpoints } \\
\hline & & & & $\mathbf{M}$ & $\mathbf{F}$ & & & \\
\hline \multirow[t]{2}{*}{ Bouras et $a l^{25}$} & \multirow[t]{2}{*}{2001} & \multirow[t]{2}{*}{ USA } & \multirow[t]{2}{*}{40} & \multirow[t]{2}{*}{4} & \multirow[t]{2}{*}{36} & $\begin{array}{l}2 \mathrm{mg} \text { vs } \\
\text { placebo }\end{array}$ & 1 & \multirow{2}{*}{$\begin{array}{l}\text { Colonic transit time, gastric } \\
\text { emptying, small bowel transit time } \\
\text { and adverse events. }\end{array}$} \\
\hline & & & & & & $\begin{array}{l}4 \mathrm{mg} \text { vs } \\
\text { placebo }\end{array}$ & & \\
\hline Emmanuel et $a l^{26}$ & 2002 & UK & 74 & NR & & $\begin{array}{l}1 \mathrm{mg} \text { vs } \\
\text { placebo }\end{array}$ & 4 & $\begin{array}{l}\text { Whole gut transit time, HR-QOL, } \\
\text { orofacial transit time, rectal } \\
\text { sensitivity and psychological state. }\end{array}$ \\
\hline \multirow[t]{2}{*}{ Sloots et $\left.a\right|^{27}$} & \multirow[t]{2}{*}{2002} & \multirow[t]{2}{*}{$\begin{array}{l}\text { The } \\
\text { Netherlands }\end{array}$} & \multirow[t]{2}{*}{37} & \multirow[t]{2}{*}{2} & \multirow[t]{2}{*}{35} & $\begin{array}{l}1 \mathrm{mg} \text { vs } \\
\text { placebo }\end{array}$ & 10 & \multirow{2}{*}{$\begin{array}{l}\text { Colonic transit time, bowel diary, } \\
\text { anorectal function, safety and } \\
\text { tolerability. }\end{array}$} \\
\hline & & & & & & $\begin{array}{l}2 \mathrm{mg} \text { vs } \\
\text { placebo }\end{array}$ & & \\
\hline Coremans et $\mathrm{al}^{28}$ & 2003 & Belgium & 53 & 1 & 52 & $\begin{array}{l}4 \mathrm{mg} \text { vs } \\
\text { placebo }\end{array}$ & 4 & $\begin{array}{l}\text { Visual analogue scale, gut transit } \\
\text { time, bowel function, safety and } \\
\text { tolerability. }\end{array}$ \\
\hline \multirow[t]{2}{*}{ Camilleri et $\mathrm{al}^{13}$} & \multirow[t]{2}{*}{2008} & \multirow[t]{2}{*}{ USA, Belgium } & \multirow[t]{2}{*}{620} & \multirow[t]{2}{*}{75} & \multirow[t]{2}{*}{545} & $\begin{array}{l}2 \mathrm{mg} \text { vs } \\
\text { placebo }\end{array}$ & \multirow[t]{2}{*}{12} & \multirow[t]{2}{*}{ SBMs/week, HR-QOL and safety. } \\
\hline & & & & & & $\begin{array}{l}4 \mathrm{mg} \text { vs } \\
\text { placebo }\end{array}$ & & \\
\hline \multirow[t]{3}{*}{ Camilleri et $a l^{29}$} & \multirow[t]{3}{*}{2009} & USA & 89 & 24 & 65 & $\begin{array}{l}0.5 \mathrm{mg} \text { vs } \\
\text { placebo }\end{array}$ & 4 & $\begin{array}{l}\text { Pharmacokinetics, adverse events } \\
\text { and ECG changes. }\end{array}$ \\
\hline & & & & & & $\begin{array}{l}1 \mathrm{mg} \text { vs } \\
\text { placebo }\end{array}$ & & \\
\hline & & & & & & $\begin{array}{l}2 \mathrm{mg} \text { vs } \\
\text { placebo }\end{array}$ & & \\
\hline Quigley et $a l^{30}$ & 2009 & Ireland & 641 & 86 & 555 & $\begin{array}{l}2 \mathrm{mg} \text { vs } \\
\text { placebo }\end{array}$ & 12 & $\begin{array}{l}\text { SBMs/week, HR-QOL, safety and } \\
\text { tolerability. }\end{array}$ \\
\hline & & & & & & $\begin{array}{l}4 \mathrm{mg} \text { vs } \\
\text { placebo }\end{array}$ & & \\
\hline Tack et $a l^{15}$ & 2009 & Belgium & 713 & 66 & 650 & $\begin{array}{l}2 \mathrm{mg} \text { vs } \\
\text { placebo }\end{array}$ & 12 & SBMs/week, HR-QOL and safety. \\
\hline & & & & & & $\begin{array}{l}4 \mathrm{mg} \text { vs } \\
\text { placebo }\end{array}$ & & \\
\hline $\begin{array}{l}\text { Müller-Lissner et } \\
\mathrm{al}^{14}\end{array}$ & 2010 & Germany & 303 & 92 & 211 & $\begin{array}{l}1 \mathrm{mg} \text { vs } \\
\text { placebo }\end{array}$ & 4 & $\begin{array}{l}\text { SBMs/week, bowel movements, } \\
\text { HR-QOL and safety. }\end{array}$ \\
\hline & & & & & & $\begin{array}{l}2 \mathrm{mg} \text { vs } \\
\text { placebo }\end{array}$ & & \\
\hline & & & & & & $\begin{array}{l}4 \mathrm{mg} \text { vs } \\
\text { placebo }\end{array}$ & & \\
\hline Ke et $a l^{31}$ & 2012 & China, Korea & 501 & 51 & 450 & $\begin{array}{l}2 \mathrm{mg} \text { vs } \\
\text { placebo }\end{array}$ & 12 & $\begin{array}{l}\text { SBMs/week, HR-QOL, safety and } \\
\text { adverse events. }\end{array}$ \\
\hline Zou et $\left.a\right|^{32}$ & 2012 & China & 313 & 36 & 277 & $\begin{array}{l}2 \mathrm{mg} \text { vs } \\
\text { placebo }\end{array}$ & 12 & SBMs/week, HR-QOL and safety. \\
\hline Mugie et $\left.a\right|^{33}$ & 2014 & $\begin{array}{l}\text { Europe } \\
\text { (multicentre) }\end{array}$ & 213 & 95 & 118 & $\begin{array}{l}2 \mathrm{mg} \text { vs } \\
\text { placebo }\end{array}$ & 8 & $\begin{array}{l}\text { SBMs/week, HR-QOL, safety and } \\
\text { tolerability. }\end{array}$ \\
\hline Piessevaux et $\left.a\right|^{34}$ & 2015 & $\begin{array}{l}\text { Europe } \\
\text { (multicentre) }\end{array}$ & 361 & 53 & 308 & $\begin{array}{l}2 \mathrm{mg} \text { vs } \\
\text { placebo }\end{array}$ & 24 & $\begin{array}{l}\text { SBMs/week, HR-QOL, bowel } \\
\text { movement frequency, adverse } \\
\text { events and safety. }\end{array}$ \\
\hline Yiannakou et $a l^{35}$ & 2015 & $\begin{array}{l}\text { Europe } \\
\text { (multicentre) }\end{array}$ & 370 & NR & & $\begin{array}{l}2 \mathrm{mg} \text { vs } \\
\text { placebo }\end{array}$ & 12 & $\begin{array}{l}\text { SBMs/week, HR-QOL, adverse } \\
\text { events and safety. }\end{array}$ \\
\hline
\end{tabular}

F, female; HR-QOL, health-related quality of life; M, male; NR, not reported; SBMs/week, spontaneous bowel movements per week.

\section{Study quality assessment}

Methodological quality assessment and outline of the 14 studies are presented in figure 2A,B. Randomised sequence generation and allocation concealment were identified adequately in all trials. These trials were placebo-controlled with either single or double blinding, except one study. ${ }^{25}$ 

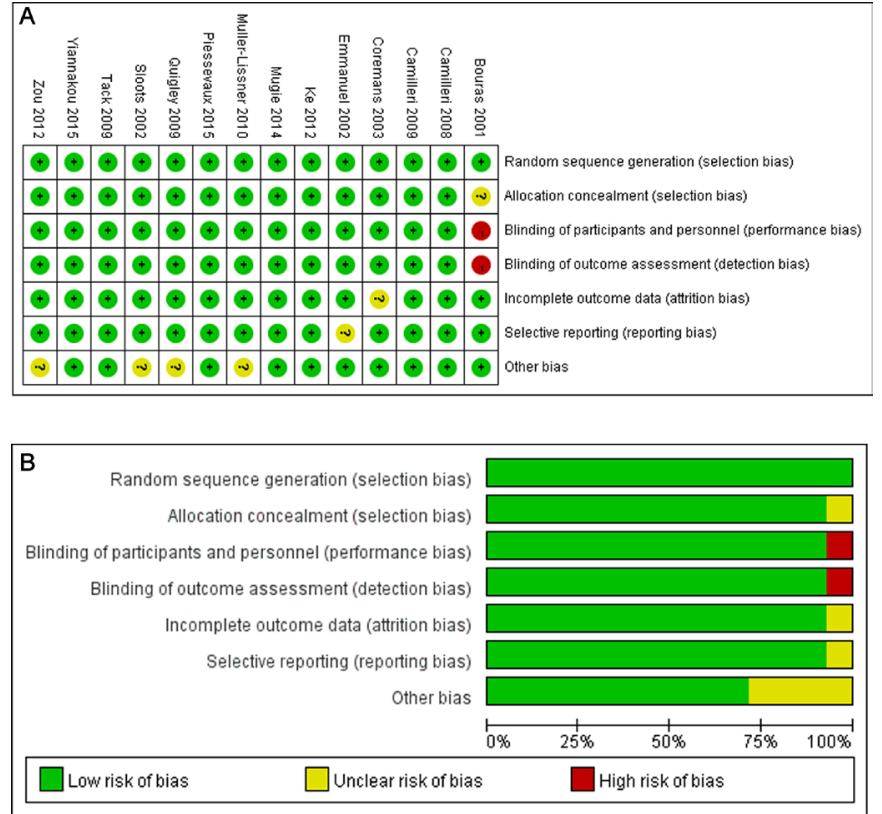

C

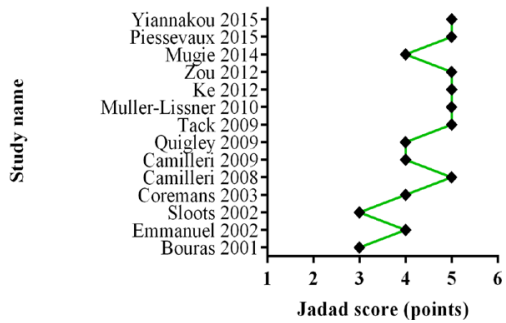

Figure 2 Methodological quality graph and summary of the included studies: (A) risk of bias summary; (B) risk of bias graph; and (C) Jadad scoring system.

Intention-to-treat (ITT) analysis was applied in nine trials. ${ }^{13-15262831323435}$ Incomplete outcomes were not detected in all studies. The assessment results of the Jadad scale are shown in figure 2C. The mean Jadad score was 4.357 points (range 3-5 points) among the included trials. All included trials were of high methodological quality.

\section{Results of meta-analysis}

SBMs per week following different doses of prucalopride versus placebo

Heterogeneity was first examined before pooled analysis. Test results revealed there was no statistically significant heterogeneity in $1 \mathrm{mg}$ (figure $3 \mathrm{~A}$ ), slight heterogeneity in $2 \mathrm{mg}\left(I^{2}=51 \%\right.$ and $Q$ test $\mathrm{p}=0.026$; figure $\left.3 \mathrm{~B}\right)$ and no significant heterogeneity in $4 \mathrm{mg} \quad\left(I^{2}<50 \%\right.$ and $Q$ test $\mathrm{p}>0.1$; figure 3C) prucalopride versus placebo. Thus, a fixedeffect model was applied for pooled analysis in $1 \mathrm{mg}$ and $4 \mathrm{mg}$ groups. A random-effect model was selected for $2 \mathrm{mg}$ pooled analysis. In the pooled meta-analysis, the incidence of SBMs per week increased significantly after using $1 \mathrm{mg}$ prucalopride $(\mathrm{Z}=2.87, \mathrm{p}=0.004 ; \mathrm{OR}=2.40,95 \% \mathrm{CI} 1.32$ to 4.37 ; figure $3 \mathrm{~A}), 2 \mathrm{mg}$ prucalopride $(\mathrm{Z}=6.63, \mathrm{p}=0.000$; $\mathrm{OR}=2.55,95 \% \mathrm{CI} 1.93$ to 3.36 ; figure $3 \mathrm{~B}$ ) and $4 \mathrm{mg}$ prucalopride $(\mathrm{Z}=6.73, \mathrm{p}=0.000 ; \mathrm{OR}=2.51,95 \%$ CI 1.92 to 3.28; figure 3C). The results demonstrated that prucalopride was able to improve SBMs per week endpoint effectively and develop an effective pharmacotherapy in the management of CIC. The results of the pooled analysis are presented in figure 3 , along with OR.

\section{TEAEs following different doses of prucalopride versus placebo}

Before pooled analysis, heterogeneity across studies was tested conventionally. The results of the heterogeneity test revealed there was no statistically significant heterogeneity in $1 \mathrm{mg}$ (figure $4 \mathrm{~A}$ ), moderate heterogeneity in $2 \mathrm{mg}\left(I^{2}=60.5 \%\right.$ and $Q$ test $\mathrm{p}=0.005$; figure $\left.4 \mathrm{~B}\right)$ and no significant heterogeneity in $4 \mathrm{mg} \quad\left(I^{2}<50 \%\right.$ and $Q$ test $\mathrm{p}>0.1$; figure 4C) prucalopride versus placebo. Thus, a fixed-effect model was applied for pooled analysis in $1 \mathrm{mg}$ and $4 \mathrm{mg}$ groups. A random-effect model was selected for $2 \mathrm{mg}$ pooled analysis. In the pooled meta-analysis, the results showed that the incidence of TEAEs increased significantly after using $2 \mathrm{mg}$ prucalopride $(\mathrm{Z}=3.57$, $\mathrm{p}=0.000$; RR: $1.20,95 \%$ CI 1.09 to 1.33 ) and $4 \mathrm{mg}$ prucalopride $(\mathrm{Z}=3.82, \mathrm{p}=0.000$; RR: $1.14,95 \%$ CI 1.07 to 1.22$)$. Meanwhile, $1 \mathrm{mg}$ prucalopride did not reach statistical significance after pooled analysis $(\mathrm{Z}=1.42, \mathrm{p}=0.154$; RR: $1.17,95 \%$ CI 0.94 to 1.44$)$. Findings are shown in figure 4 , along with RR.

\section{Bayesian analysis for optimal dose of prucalopride}

Bayesian methodology was used to determine the optimal dose of prucalopride in the treatment of CIC through multiple-treatment meta-analysis models. Different doses of prucalopride reported in order of SBMs per week and TEAEs ranked according to SUCRA are shown in figure 5. We reported the consistency model results of SBMs per week and TEAEs after confirming there was no statistically significant inconsistency and the three Markov chains converged (potential scale reduction factor $=1$ ). SBMs per week and TEAEs of $1 \mathrm{mg}, 2 \mathrm{mg}$ and $4 \mathrm{mg}$ prucalopride reached statistical significance compared with placebo. After statistical comparison, we revealed that $1 \mathrm{mg}$ prucalopride demonstrated the maximum frequency of SBMs per week (OR: 3.31, 95\% CrI 1.72 to 6.16 , table 2; probability rank=0.70, figure $5 \mathrm{~A}$ ) indirectly compared with $2 \mathrm{mg}$ and $4 \mathrm{mg}$ prucalopride. In terms of TEAEs, $1 \mathrm{mg}$ prucalopride also holds the highest incidence (RR: 1.72, 95\% CrI 1.02 to 2.92, table 2; probability rank=0.47, figure $5 \mathrm{~B}$ ) compared with $2 \mathrm{mg}$ and $4 \mathrm{mg}$ prucalopride indirectly. Meanwhile, $4 \mathrm{mg}$ prucalopride has the second probability sequence (probability rank=0.33; figure 5B).

\section{Sensitivity analysis}

We carried out sensitivity analysis to verify the robustness of our results. The results are shown in figure 6 . We performed sensitivity analysis via the leave-one-out procedure each time, and the outcomes of the sensitivity analysis showed that exclusion of any study did not significantly account for heterogeneity, demonstrating our results were robust to some extent.

\section{Publication bias}

Egger's test and contour-enhanced funnel plot were employed to assess potential publication bias. First, 
A

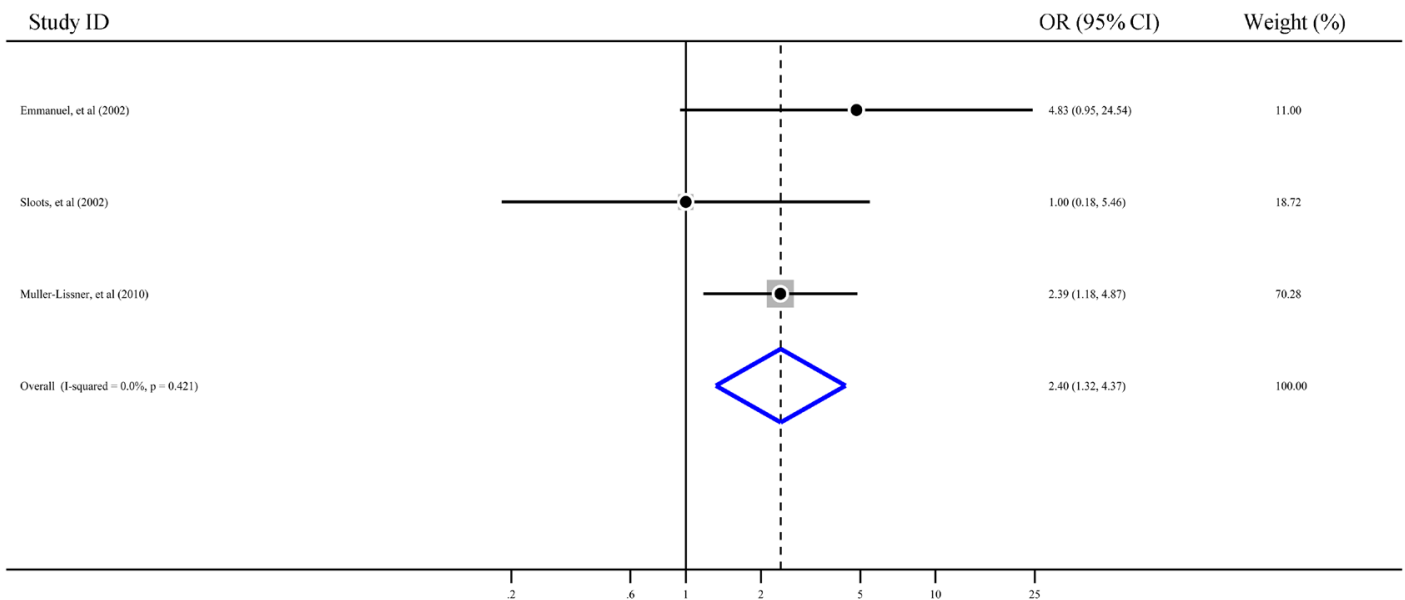

B

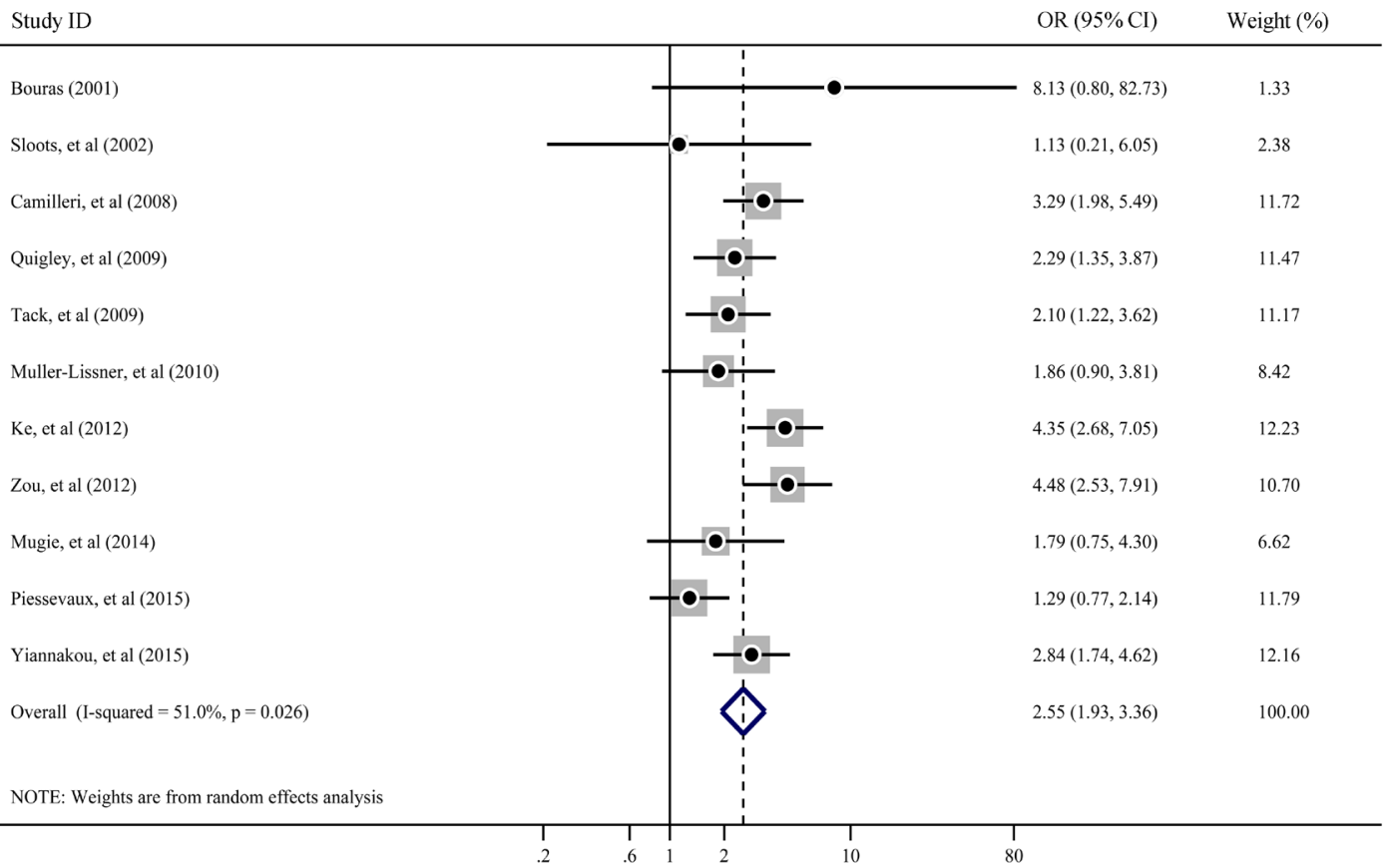

C

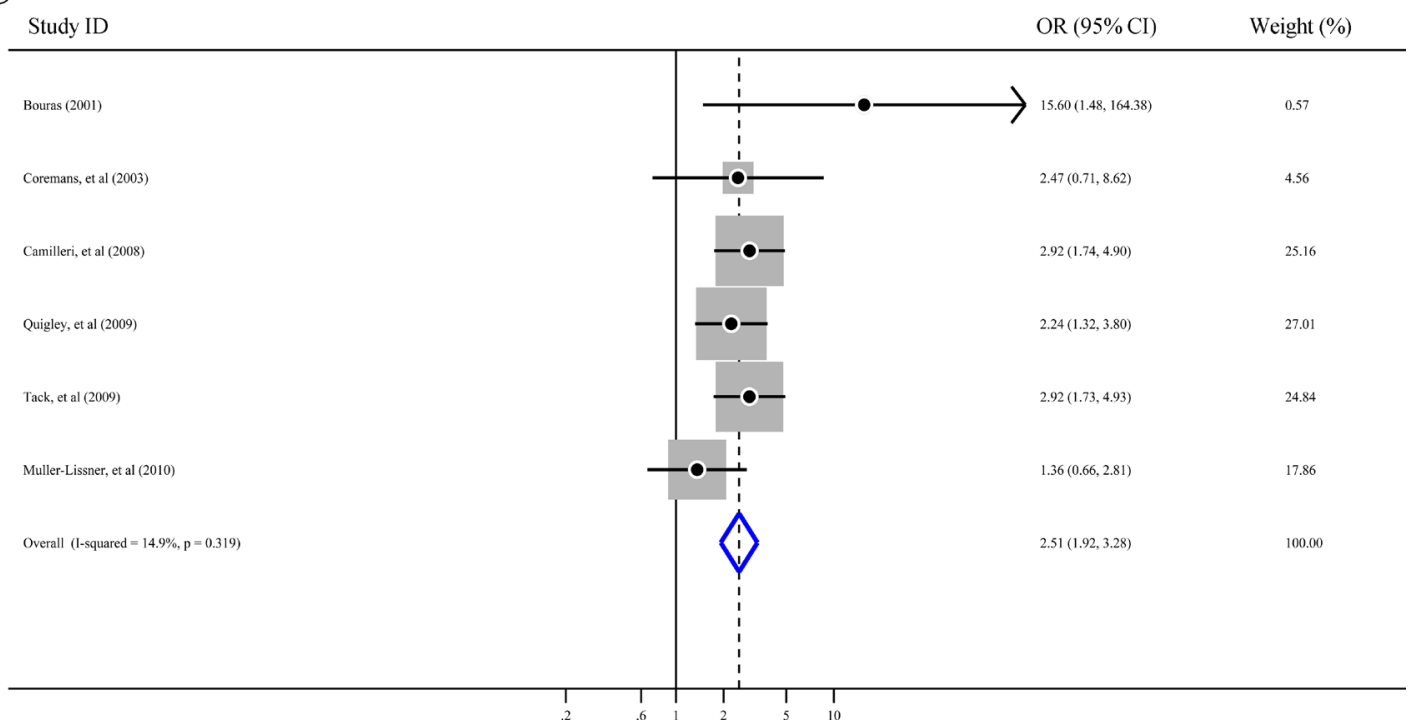

Figure 3 Forest plot for SBMs per week following different doses of prucalopride. (A) $1 \mathrm{mg}$ prucalopride vs placebo; (B) $2 \mathrm{mg}$ prucalopride vs placebo; and (C) $4 \mathrm{mg}$ prucalopride vs placebo. SBMs, spontaneous bowel movements. 
A study ID

$\mathrm{RR}(95 \% \mathrm{CI})$

Weight \%

Sloots, et al (2002)

Camilleri, et al (2009)

Muller-Lissner, et al (2010)

Overall (I-squared $=0.0 \%, p=0.878)$

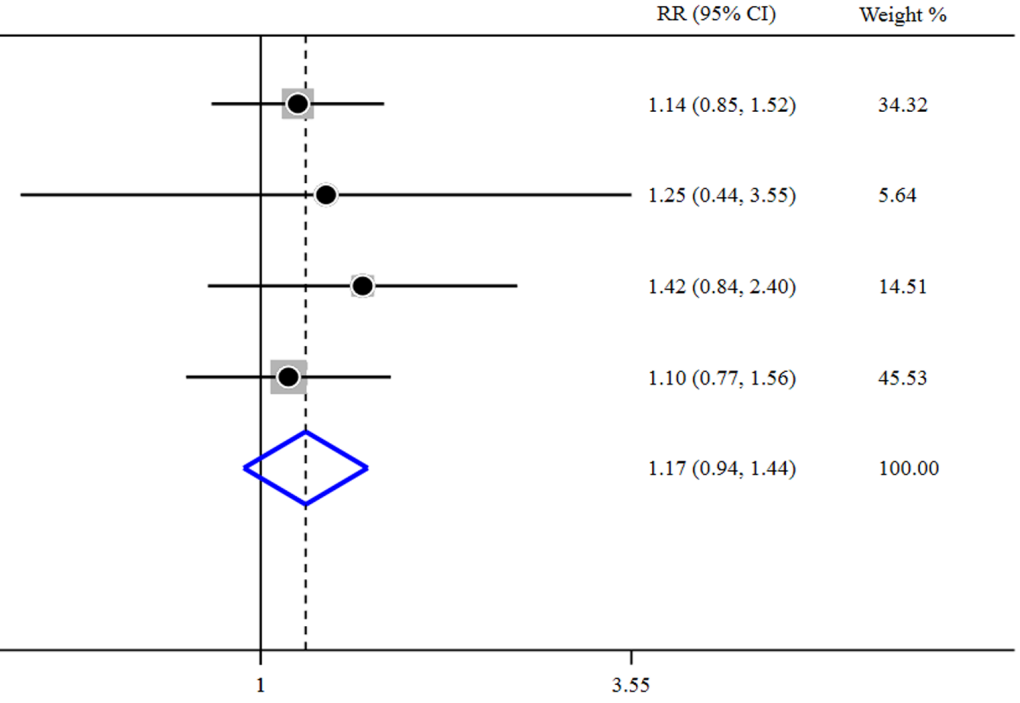

B Study ID

RR $(95 \% \mathrm{CI}) \quad$ Weight $\%$

Sloots, et al (2002)

Camilleri, et al (2008)

Camilleri, et al (2009)

Quigley, et al (2009)

Tack, et al (2009)

Muller-Lissner, et al (2010)

$\mathrm{Ke}$, et al (2012)

Zou, et al (2012)

Mugie, et al (2014)

Piessevaux, et al (2015)

Yiannakou, et al (2015)

Overall (I-squared $=60.5 \%, \mathrm{p}=0.005)$

NOTE: Weights are from random effects analysis

$\begin{array}{lll}1 & 1 \\ .354 & 1 & 2.83\end{array}$

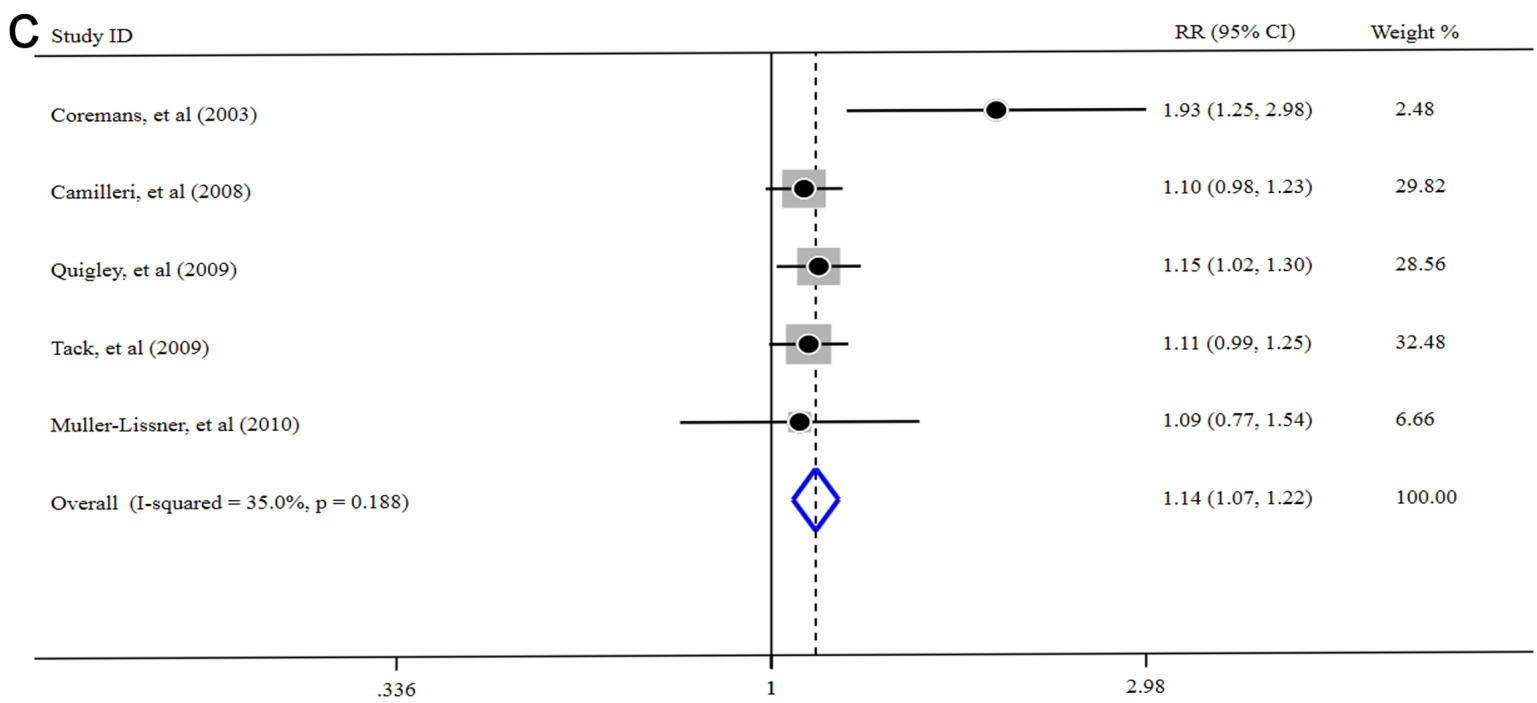

$1.08(0.41,2.83)-1.05$

$1.38(0.82,2.35) \quad 3.06$

$1.22(1.09,1.38) \quad 14.82$

$1.06(0.94,1.20) \quad 14.66$

$0.87(0.59,1.29) \quad 4.98$

$1.56(1.28,1.90) \quad 10.94$

$1.81(1.34,2.43) \quad 7.17$

$1.15(0.94,1.40) \quad 10.85$

$0.99(0.78,1.27) \quad 8.98$

$1.23(0.95,1.60) \quad 8.31$

$1.20(1.09,1.33) \quad 100.00$

. 1

83

Figure 4 Forest plot for TEAEs following different doses of prucalopride. (A) $1 \mathrm{mg}$ prucalopride versus placebo; (B) $2 \mathrm{mg}$ prucalopride versus placebo; and (C) $4 \mathrm{mg}$ prucalopride versus placebo. RR, risk ratio; TEAEs, treatment-emergent adverse events. 

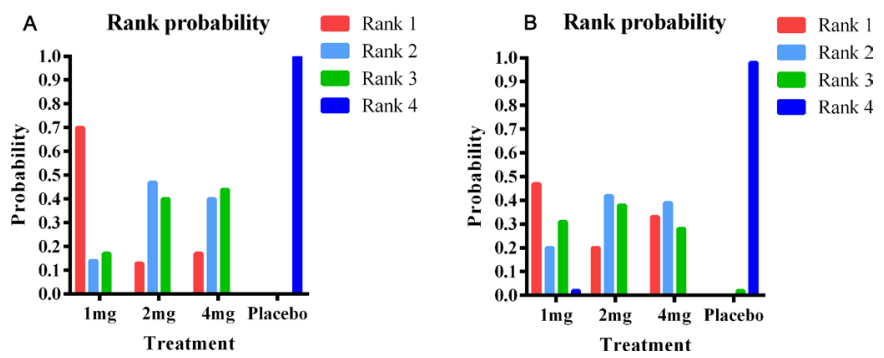

Figure 5 Bayesian analysis of SBMs per week and TEAEs following different doses of prucalopride: (A) probability rank of SBMs per week and (B) probability rank of TEAEs. SBMs, spontaneous bowel movements; TEAEs, treatment-emergent adverse events.

Egger's test was applied to assess potential publication bias for pooled SBMs per week and TEAEs as the results are quantitative. The results of the Egger's test revealed there was no publication bias in both synthesised analysis $\left(\mathrm{p}_{\mathrm{SBMs} \text { per week }}=0.929, \mathrm{p}_{\mathrm{TEAES}}=0.483\right.$; figure $\left.7 \mathrm{~A}, \mathrm{~B}\right)$. Then, contour-enhanced funnel plot, which added conventional milestones in levels of statistical significance $(\mathrm{p}<0.01, \mathrm{p}<0.05, \mathrm{p}<0.1$ or $\mathrm{p}>0.1)$ to funnel plots, was used to distinguish detailed reasons for publication bias. The results indicated many missing studies are of higher statistical significance $(\mathrm{p}<0.01$; figure $7 \mathrm{C}, \mathrm{D})$, which suggested the origin of asymmetry may be more likely to be due to undetected factors rather than publication bias. Finally, we traced the original research again, speculating that studies with a small sample size and with ITT analysis missing in many studies may account for the undetected bias. These factors may have a potential impact on our conclusions.

\section{Meta-regression analysis}

Meta-regression was performed to assess the effect of underlying confounding factors on pooled effect estimation and to seek the sources of heterogeneity for SBMs per week and TEAEs following $2 \mathrm{mg}$ prucalopride. We premeditated the following covariates as potential factors: (1) different patient ethnicity (Asian and Western); (2) total sample size $(n \geq 200$ and $n<200)$; (3) different courses of taking prucalopride; and (4) ITT analysis used. Overall, univariate analysis indicated ethnicity in different regions had a significant influence on the results of $2 \mathrm{mg}$ prucalopride between SBMs per week ( $\mathrm{p}=0.020$; figure $8 \mathrm{~A}$ and table 3 ) and TEAEs $(p=0.002$; figure $8 \mathrm{~B}$ and table 3$)$. The remaining three variables influenced neither the pooled effect of SBMs per week nor the TEAEs significantly. Multivariate meta-regression was then used to evaluate the impact of various covariates on the pooled effect of SBMs per week and TEAEs. For SBMs per week, four covariates did not affect the relationship between $2 \mathrm{mg}$ prucalopride and SBMs per week outcome $(\mathrm{p}=0.058$; table 3$)$ and the heterogeneity did not stem from this model. For TEAEs, multivariate analysis revealed that the relationship between $2 \mathrm{mg}$ prucalopride and the TEAE endpoint was influenced by the covariate of ethnicity in different regions ( $\mathrm{p}=0.017$; table 3 ), indicating the heterogeneity may originate from this covariate.

\section{DISCUSSION}

Overall, the findings of the current study acknowledge that patients with CIC can be treated with prucalopride efficaciously, whether $1 \mathrm{mg}$, $2 \mathrm{mg}$ or $4 \mathrm{mg}$ doses are used. The certainty of conclusion from the current study is mainly reflected in the following two aspects. First, the proportion of SBMs per week was employed as the cardinal endpoint in the current study for pooled metaanalysis. According to the definition of SBMs per week based on the Rome criteria, SBMs per week can incorporate anorectal assessments of rectal evacuation and subjective symptoms completely. ${ }^{36}{ }^{37}$ In the current study, SBMs per week increased significantly after using $1 \mathrm{mg}$ $(\mathrm{OR}=2.40,95 \%$ CI 1.32 to 4.37$), 2 \mathrm{mg}(\mathrm{OR}=2.55,95 \% \mathrm{CI}$ 1.93 to 3.36$)$ and $4 \mathrm{mg}(\mathrm{OR}=2.51,95 \%$ CI 1.92 to 3.28$)$ prucalopride. The results demonstrated that patients with CIC may benefit from prucalopride using different doses. Second, additional indicators of CIC, such as the Patient Assessment of Constipation Quality of Life and the Patient Assessment of Constipation Symptoms, also got ameliorated according to original researches. ${ }^{13} 3033-35$

Table 2 Bayesian analysis of SBMs/week and TEAEs following different doses of prucalopride

\begin{tabular}{|c|c|c|c|}
\hline $1 \mathrm{mg}$ & $\begin{array}{l}\mathrm{RR}(95 \% \mathrm{Crl}) \\
\mathbf{1 . 7 2}(\mathbf{1 . 0 2} \text { to } \mathbf{2 . 9 2})\end{array}$ & $\begin{array}{l}\mathrm{RR}(95 \% \mathrm{Crl}) \\
\mathbf{1 . 6 1}(\mathbf{1 . 2 8} \text { to } 2.06)\end{array}$ & $\begin{array}{l}\mathrm{RR}(95 \% \mathrm{Crl}) \\
\mathbf{1 . 6 7}(\mathbf{1 . 2 3} \text { to } \mathbf{2 . 4 0 )}\end{array}$ \\
\hline OR (95\% Crl) & $2 \mathrm{mg}$ & $\mathrm{RR}(95 \% \mathrm{Crl})$ & $\mathrm{RR}(95 \% \mathrm{Crl})$ \\
\hline OR (95\% Crl) & OR (95\% Crl) & $4 \mathrm{mg}$ & RR (95\% Crl) \\
\hline 1.27 (0.63 to 2.48$)$ & $1.00(0.70$ to 1.43$)$ & & 1.07 (0.63 to 1.82$)$ \\
\hline 3.31 (1.72 to 6.16$)$ & 2.61 (1.98 to 3.43 ) & 2.60 (1.80 to 3.73$)$ & \\
\hline
\end{tabular}

Significant results are in bold.

Treatment; SBMs/week, OR (95\% Crl); TEAEs, RR (95\% Crl).

95\% Crl, 95\% credible interval; RR, risk ratio; SBMs/week, spontaneous bowel movements per week; TEAEs, treatment-emergent adverse events. 

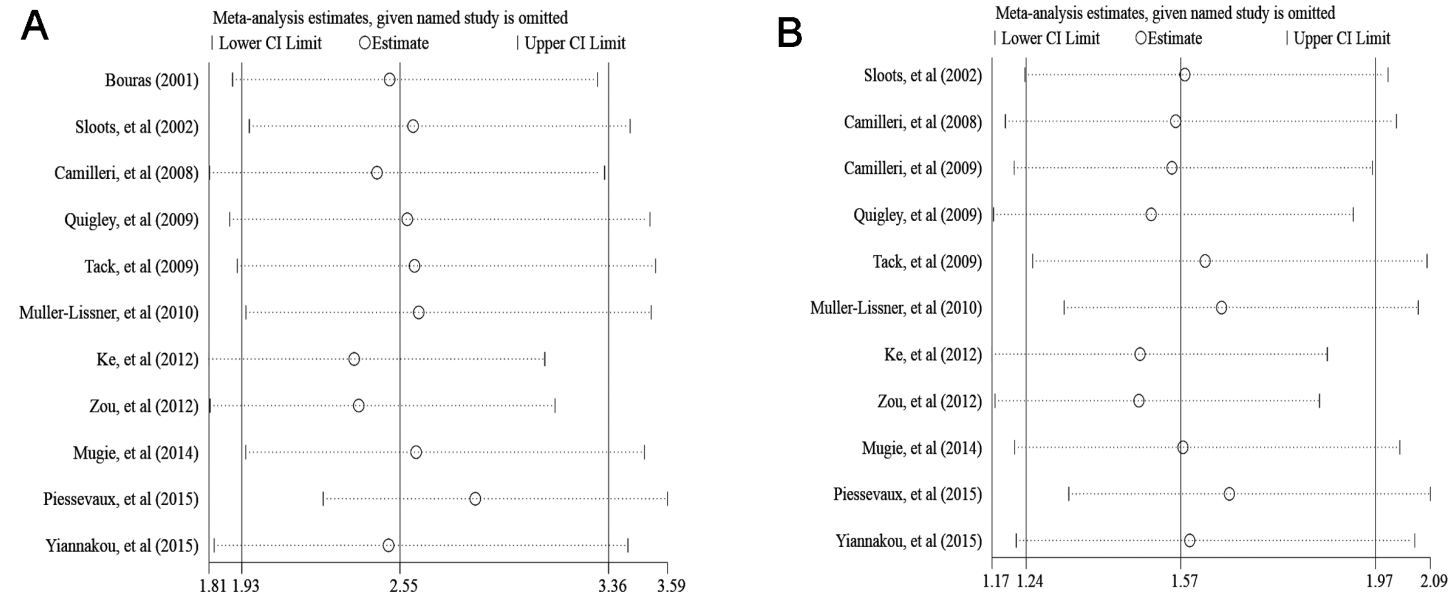

Figure 6 Sensitivity analysis for (A) spontaneous bowel movements per week and (B) treatment-emergent adverse events.

Third, a prospective, randomised, cross-over study with $2 \mathrm{mg}$ prucalopride versus polyethylene glycol $3350+$ electrolytes (PEG3350) also demonstrated prucalopride had obvious advantages over PEG3350 in promoting highamplitude propagating contractions in patients with CIC. ${ }^{38}$ All supporting evidence mentioned above demonstrates prucalopride should be an effective pharmacotherapy in the management of CIC. We tried to provide the optimal dose of prucalopride in CIC management through Bayesian framework models. The results revealed that $1 \mathrm{mg}, 2 \mathrm{mg}$ and $4 \mathrm{mg}$ prucalopride reached statistical significance compared with placebo, which is consistent with a previous pairwise meta-analysis. Moreover, we revealed $1 \mathrm{mg}$ prucalopride obtained the maximum frequency of SBMs per week (OR: 3.31, 95\% CrI 1.72 to 6.16 , probability rank $=0.70$ ) indirectly compared with $2 \mathrm{mg}$ and $4 \mathrm{mg}$ doses. A previous study showed prucalopride applied at $4 \mathrm{mg}$ dose in the experiment arm did not provide a dose-dependent benefit in SBMs per week over $2 \mathrm{mg}$ dose (4mg $28.4 \%$ vs $2 \mathrm{mg} \mathrm{30.9 \% ).}{ }^{13}$ Another study also failed to achieve higher frequency of SBMs per week with a dose of $4 \mathrm{mg}$ over the $2 \mathrm{mg}$ dose ( $4 \mathrm{mg} 24 \%$ vs $2 \mathrm{mg}$

A

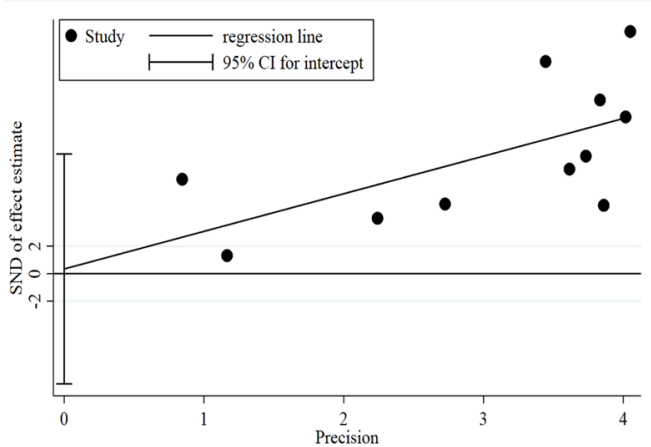

C

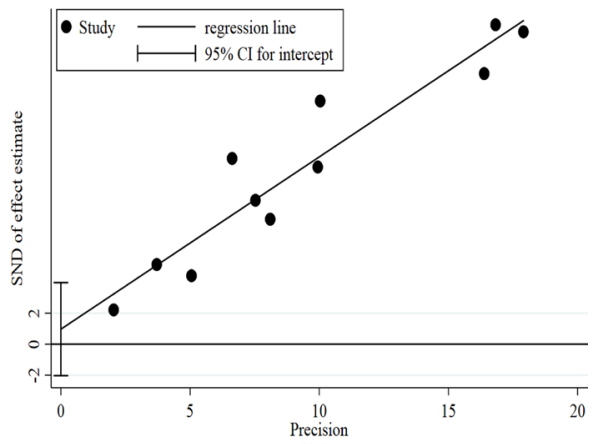

D
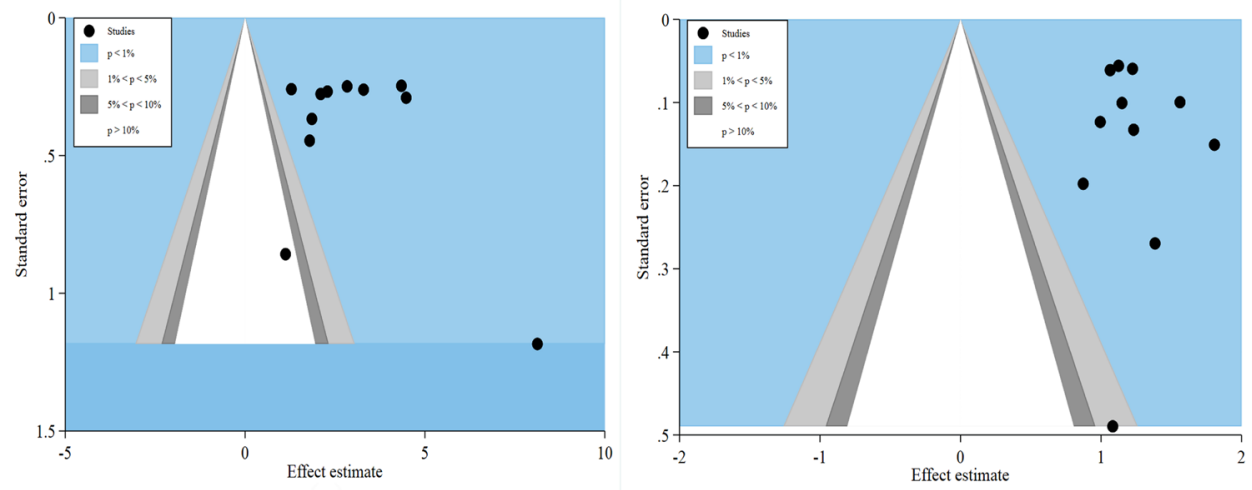

Figure 7 Publication bias assessment. (A) Egger's test for SBMs per week; (B) Egger's test for TEAEs; (C) contour-enhanced funnel plot for SBMs per week; and (D) contour-enhanced funnel plot for TEAEs. SBMs, spontaneous bowel movements; TEAEs, treatment-emergent adverse events. 

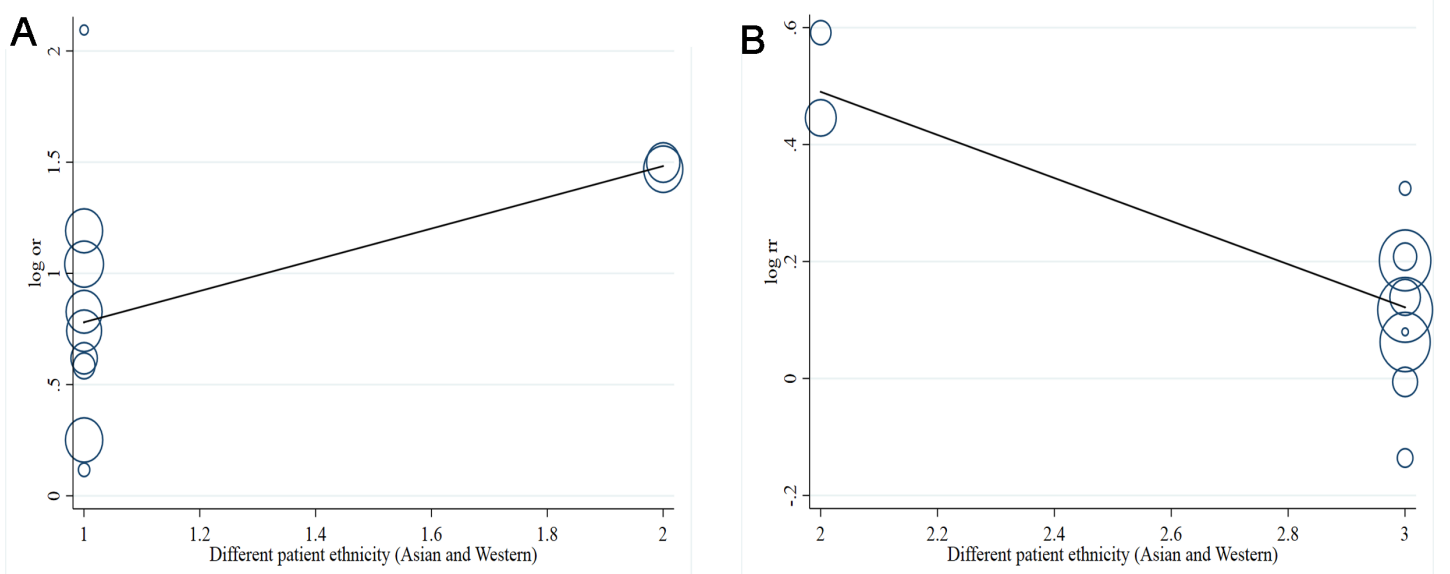

Figure 8 Univariate meta-regression analysis: (A) spontaneous bowel movements per week of 2 mg prucalopride and (B) treatment-emergent adverse events of $2 \mathrm{mg}$ prucalopride. $\mathrm{RR}$, risk ratio.

24\%). ${ }^{30}$ Considering all these, we arrived at the conclusion that there is no incremental benefit in prucalopride application and that $1 \mathrm{mg}$ dose could be safer in treating CIC.

TEAEs related to prucalopride consumption were evaluated in this meta-analysis. When reported, headache, nausea, diarrhoea and abdominal pain are the most common TEAEs following prucalopride consumption. ${ }^{13152930}$ However, the severity of these TEAEs was slight or mild mainly during the first 24 hours of taking and lasts ephemerally. ${ }^{13039}$ Our findings revealed the incidence of TEAEs increased significantly after using $2 \mathrm{mg}$ dose (RR: $1.20,95 \%$ CI 1.09 to 1.33 ) and $4 \mathrm{mg}$ dose (RR: $1.14,95 \%$ CI 1.07 to 1.22 ). Meanwhile, the $1 \mathrm{mg}$ dose did not reach statistical significance after pooled analysis (RR: 1.17, $95 \%$ CI 0.94 to 1.44). Bayesian framework analysis showed the $1 \mathrm{mg}$ dose holds the highest incidence (RR: 1.72, 95\% CrI 1.02 to 2.92 , probability rank=0.47) compared with the $2 \mathrm{mg}$ and $4 \mathrm{mg}$ doses indirectly. Meanwhile, the $4 \mathrm{mg}$ dose has the second probability sequence (RR: 1.61, 95\% CrI 1.28 to 2.06 , probability rank $=0.33$ ) and the $2 \mathrm{mg}$ dose ranked the lowest (RR: $1.67,95 \%$ CrI 1.23 to 2.40, probability rank=0.2). Clearly, the probability rank of $1 \mathrm{mg}$, $2 \mathrm{mg}$ and $4 \mathrm{mg}$ doses is lower than $50 \%$. TEAEs of 5 -HT4 receptor agonists have received considerable attention, particularly cardiovascular adverse events. ${ }^{29}{ }^{40}$ An earlier study suggested that no consistent or clinically relevant TEAE divergences were noted in ECG components versus baseline and placebo groups, even in $88 \%$ of volunteers with a history of cardiovascular diseases. ${ }^{29} \mathrm{~A}$ thorough QT study ${ }^{40}$ based on the ICH E14 guidance, also demonstrated no evidence of QT prolongation or proarrhythmic potential for prucalopride application. This evidence suggests prucalopride has good tolerance in cardiovascular system and overall TEAEs.

\begin{tabular}{|c|c|c|c|c|c|c|c|c|}
\hline \multirow[b]{2}{*}{ Covariates } & \multicolumn{4}{|c|}{$2 \mathrm{mg}$ SBMs per week, OR (11 studies) } & \multicolumn{4}{|c|}{ 2mg TEAEs, RR* (11 studies) } \\
\hline & Coefficient & $95 \% \mathrm{Cl} \dagger$ & $P$ value & Tau2 & Coefficient & $95 \% \mathrm{Cl} \dagger$ & $\begin{array}{l}P \\
\text { value }\end{array}$ & Tau2 \\
\hline \multicolumn{9}{|l|}{ Univariate analysis } \\
\hline Ethnicity in different regions & 0.70 & 0.14 to 1.27 & 0.020 & 0.023 & 0.24 & 0.03 to 0.46 & 0.002 & 0.006 \\
\hline Total sample size & 0.00 & -0.001 to 0.004 & 0.332 & 0.095 & 0.08 & -0.55 to 0.71 & 0.786 & 0.021 \\
\hline Courses of taking prucalopride & 2.09 & -1.01 to 5.20 & 0.144 & 0.025 & 0.14 & -0.35 to 0.63 & 0.514 & 0.026 \\
\hline ITT analysis & 0.10 & -1.10 to 1.30 & 0.856 & 0.114 & 0.01 & -0.37 to 0.38 & 0.953 & 0.024 \\
\hline \multicolumn{9}{|l|}{ Multivariate analysis } \\
\hline Ethnicity in different regions & 0.70 & -0.03 to 1.45 & 0.058 & NA & 0.31 & 0.07 to 0.55 & 0.017 & NA \\
\hline Total sample size & 0.00 & -1.97 to 1.97 & 0.999 & NA & 0.37 & -0.33 to 1.07 & 0.688 & NA \\
\hline Courses of taking prucalopride & -0.04 & -0.34 to 0.25 & 0.723 & NA & 0.09 & -0.03 to 0.22 & 0.108 & NA \\
\hline ITT analysis & 0.05 & -0.78 to 0.89 & 0.873 & NA & -0.04 & -0.25 to 0.18 & 0.688 & NA \\
\hline Omnibus test for moderators & & & 0.897 & 0.051 & & & 0.108 & 0.003 \\
\hline
\end{tabular}

Significant results are in bold.

ITT, intention-to-treat; NA, not applicable; RR, risk ratio; SBMs, spontaneous bowel movements; TEAEs, treatment-emergent adverse events. 
The current study exerts more attention to the incremental benefit of prucalopride. Previous work has provided critical findings that prucalopride is able to treat CIC effectively with mild, transitory and slight by-effects. ${ }^{41-44}$ However, the dose-related trends in efficacy assessment and TEAEs have not been explored. In this study, the results revealed that there is no incremental benefit in prucalopride application and $1 \mathrm{mg}$ dose is suggested to be given at commencement. Furthermore, clinical evidence from China with 313 samples $^{32}$ was included in the current study. The study of Zou et $a l^{2}$ could be an eventful supplement to current evidence and fill the gap in knowledge about use of prucalopride in China, even in the Asian region. Finally, the current study is the most extensive meta-analysis based on 14 well-designed RCTs with 4328 patients, providing more powerful evidence in favour of the integrated analysis.

Potential limitations of this integrated analysis should be considered. Fourteen included trials with variable duration (from 1 to 24 weeks) measured endpoints by different criteria, such as colonic transit time, rectal sensitivity, anorectal function and SBMs per week, increasing the risk of measurement bias. Meanwhile, undetected bias predicted by contour-enhanced funnel plot showed studies with a small sample size and with ITT analysis missing may account for potential bias. These factors may have a potential impact on our conclusions. Metaregression by univariate and multivariate analyses found different patient ethnicities (Asian and Western) were a potential covariate causing moderate heterogeneity $\left(I^{2}=60.5 \%\right)$ and de-escalate the validity of the results of the current analysis.

All in all, this is the largest meta-analysis with 4328 patients from 14 high-quality RCTs and provides pivotal evidence that prucalopride given at $1 \mathrm{mg}$ dose can manage CIC effectively. Furthermore, no incremental benefit was detected in prucalopride application. When accepting the conclusions of this study, the methodological limitations should be considered at the same time. It is widely recognised that CIC is a chronic disease of intestinal dysfunction and requires long-term medication, so more RCTs of larger scale and with longer-term efficacy assessments are needed to balance the risk-benefit profile of prucalopride in the treatment of CIC.

\section{Author affiliations \\ ${ }^{1}$ College of Clinical Medicine, Chengdu University of Traditional Chinese Medicine, Chengdu, China \\ ${ }^{2}$ China Academy of Chinese Medical Sciences, Beijing, China \\ ${ }^{3}$ The First Affiliated Hospital, Guizhou University of Traditional Chinese Medicine, Guiyang City, China \\ ${ }^{4}$ Chengdu University of Traditional Chinese Medicine, Chengdu, China \\ ${ }^{5}$ th Medical Center of Chinese PLA General Hospital, Fengtai-Qu, China \\ ${ }^{6}$ Chengdu Anorectal Hospital, Chengdu, China \\ ${ }^{7}$ Guizhou University of Traditional Chinese Medicine, Guiyang City, China}

Acknowledgements Our greatest acknowledgement goes to the authors who made detailed data available for this meta-analysis and all our colleagues in this study for their hard work.
Contributors TY, LKW and XJW performed the search and drafted the manuscript. TY and BYC performed the data extraction and analysed the data. TY, TX and DXY designed the study and amended the original draft

Funding The authors have not declared a specific grant for this research from any funding agency in the public, commercial or not-for-profit sectors.

Competing interests None declared.

Patient and public involvement Patients and/or the public were not involved in the design, or conduct, or reporting, or dissemination plans of this research.

Patient consent for publication Not required.

Provenance and peer review Not commissioned; externally peer reviewed.

Data availability statement All data relevant to the study are included in the article or uploaded as supplementary information.

Open access This is an open access article distributed in accordance with the Creative Commons Attribution Non Commercial (CC BY-NC 4.0) license, which permits others to distribute, remix, adapt, build upon this work non-commercially, and license their derivative works on different terms, provided the original work is properly cited, appropriate credit is given, any changes made indicated, and the use is non-commercial. See: http://creativecommons.org/licenses/by-nc/4.0/.

ORCID iD

Tao Yang http://orcid.org/0000-0002-5787-2542

\section{REFERENCES}

1 Suares NC, Ford AC. Prevalence of, and risk factors for, chronic idiopathic constipation in the community: systematic review and meta-analysis. Am J Gastroenterol 2011;106:1582-91.

2 Talley NJ, Fleming KC, Evans JM, et al. Constipation in an elderly community: a study of prevalence and potential risk factors. Am J Gastroenterol 1996;91:19-25.

3 Chang L, Toner BB, Fukudo S, et al. Gender, age, society, culture, and the patient's perspective in the functional gastrointestinal disorders. Gastroenterology 2006;130:1435-46.

4 Rao SSC, Tuteja AK, Vellema T, et al. Dyssynergic defecation: demographics, symptoms, stool patterns, and quality of life. J Clin Gastroenterol 2004;38:680-5.

5 Singh $\mathrm{G}$, Lingala V, Wang $\mathrm{H}$, et al. Use of health care resources and cost of care for adults with constipation. Clin Gastroenterol Hepatol 2007:5:1053-8.

6 Guerin A, Carson RT, Lewis B, et al. The economic burden of treatment failure amongst patients with irritable bowel syndrome with constipation or chronic constipation: a retrospective analysis of a Medicaid population. J Med Econ 2014;17:577-86.

7 Jones MP, Talley NJ, Nuyts G, et al. Lack of objective evidence of efficacy of laxatives in chronic constipation. Dig Dis Sci 2002;47:2222-30.

8 Chen F, Yu Y, Wang P, et al. Brain-derived neurotrophic factor accelerates gut motility in slow-transit constipation. Acta Physiol 2014;212:226-38.

9 Wald A, Scarpignato C, Mueller-Lissner S, et al. A multinational survey of prevalence and patterns of laxative use among adults with self-defined constipation. Aliment Pharmacol Ther 2008;28:917-30.

10 Quigley EMM, Neshatian L. Advancing treatment options for chronic idiopathic constipation. Expert Opin Pharmacother 2016;17:501-11.

11 Bassotti G, Usai Satta P, Bellini M. Prucalopride for the treatment of constipation: a view from 2015 and beyond. Expert Rev Gastroenterol Hepatol 2019;13:257-62.

12 Bouras EP, Camilleri M, Burton DD, et al. Selective stimulation of colonic transit by the benzofuran $5 \mathrm{HT} 4$ agonist, prucalopride, in healthy humans. Gut 1999;44:682-6.

13 Camilleri M, Kerstens R, Rykx A, et al. A placebo-controlled trial of prucalopride for severe chronic constipation. $N$ Engl J Med 2008;358:2344-54.

14 Müller-Lissner S, Rykx A, Kerstens R, et al. A double-blind, placebocontrolled study of prucalopride in elderly patients with chronic constipation. Neurogastroenterol Motil 2010;22:991-e255.

15 Tack J, van Outryve M, Beyens G, et al. Prucalopride (Resolor) in the treatment of severe chronic constipation in patients dissatisfied with laxatives. Gut 2009;58:357-65.

16 Jiang $C$, Xu Q, Wen X, et al. Current developments in pharmacological therapeutics for chronic constipation. Acta Pharm Sin B 2015:5:300-9.

17 Moher D, Liberati A, Tetzlaff J, et al. Preferred reporting items for systematic reviews and meta-analyses: the PRISMA statement. PLoS Med 2009;6:e1000097. 
18 Jadad AR, Moore RA, Carroll D, et al. Assessing the quality of reports of randomized clinical trials: is blinding necessary? Control Clin Trials 1996;17:1-12.

19 Harbord RM, Egger M, Sterne JAC. A modified test for small-study effects in meta-analyses of controlled trials with binary endpoints. Stat Med 2006;25:3443-57.

20 Egger M, Davey Smith G, Schneider M, et al. Bias in meta-analysis detected by a simple, graphical test. BMJ 1997;315:629-34.

21 Peters JL, Sutton AJ, Jones DR, et al. Contour-enhanced metaanalysis funnel plots help distinguish publication bias from other causes of asymmetry. J Clin Epidemiol 2008;61:991-6.

22 Salanti G, Ades AE, loannidis JPA. Graphical methods and numerical summaries for presenting results from multiple-treatment metaanalysis: an overview and tutorial. J Clin Epidemiol 2011;64:163-71.

$23 \mathrm{Lu} \mathrm{G}$, Ades AE. Combination of direct and indirect evidence in mixed treatment comparisons. Stat Med 2004;23:3105-24.

24 Gelman A, Rubin DB. Markov chain Monte Carlo methods in biostatistics. Stat Methods Med Res 1996;5:339-55.

25 Bouras EP, Camilleri M, Burton DD, et al. Prucalopride accelerates gastrointestinal and colonic transit in patients with constipation without a rectal evacuation disorder. Gastroenterology 2001;120:354-60.

26 Emmanuel AV, Roy AJ, Nicholls TJ, et al. Prucalopride, a systemic enterokinetic, for the treatment of constipation. Aliment Pharmacol Ther 2002;16:1347-56.

27 Sloots CEJ, Poen AC, Kerstens R, et al. Effects of prucalopride on colonic transit, anorectal function and bowel habits in patients with chronic constipation. Aliment Pharmacol Ther 2002;16:759-67.

28 Coremans G, Kerstens R, De Pauw M, et al. Prucalopride is effective in patients with severe chronic constipation in whom laxatives fail to provide adequate relief. Results of a double-blind, placebocontrolled clinical trial. Digestion 2003;67:82-9.

29 Camilleri M, Beyens G, Kerstens R, et al. Safety assessment of prucalopride in elderly patients with constipation: a double-blind, placebo-controlled study. Neurogastroenterol Motil 2009;21:e117:1 256-e117.

30 Quigley EMM, Vandeplassche L, Kerstens R, et al. Clinical trial: the efficacy, impact on quality of life, and safety and tolerability of prucalopride in severe chronic constipation--a 12-week, randomized, double-blind, placebo-controlled study. Aliment Pharmacol Ther 2009;29:315-28.

31 Ke M, Zou D, Yuan Y, et al. Prucalopride in the treatment of chronic constipation in patients from the Asia-Pacific region: a randomized, double-blind, placebo-controlled study. Neurogastroenterol Motil 2012;24:999-e541.
32 Zou DW, MY K, Yuan YZ. Prucalopride in the treatment of Chinese patients with chronic constipation : a randomised, double-blind, placebo-controlled study. Chin.J.Dig 2012;32:847-51.

33 Mugie SM, Korczowski B, Bodi $\mathrm{P}$, et al. Prucalopride is no more effective than placebo for children with functional constipation. Gastroenterology 2014;147:1285-95.

34 Piessevaux $\mathrm{H}$, Corazziari $\mathrm{E}$, Rey $\mathrm{E}$, et al. A randomized, doubleblind, placebo-controlled trial to evaluate the efficacy, safety, and tolerability of long-term treatment with prucalopride. Neurogastroenterol Motil 2015;27:805-15.

35 Yiannakou $\mathrm{Y}$, Piessevaux $\mathrm{H}$, Bouchoucha $\mathrm{M}$, et al. A randomized, double-blind, placebo-controlled, phase 3 trial to evaluate the efficacy, safety, and tolerability of prucalopride in men with chronic constipation. Am J Gastroenterol 2015;110:741-8.

36 Rao SS, Bharucha AE, Chiarioni G, et al. Functional anorectal disorders. Gastroenterology 2016 doi:10.1053/j.gastro.2016.02.009

37 Mearin F, Lacy BE, Chang L. Bowel disorders. Gastroenterology 2016.

38 Miner PB, Camilleri M, Burton D, et al. Prucalopride induces highamplitude propagating contractions in the colon of patients with chronic constipation: a randomized study. Neurogastroenterol Motil 2016;28:1341-8.

39 Poen AC, Felt-Bersma RJ, Van Dongen PA, et al. Effect of prucalopride, a new enterokinetic agent, on gastrointestinal transit and anorectal function in healthy volunteers. Aliment Pharmacol Ther 1999;13:1493-7.

40 Mendzelevski B, Ausma J, Chanter DO, et al. Assessment of the cardiac safety of prucalopride in healthy volunteers: a randomized, double-blind, placebo- and positive-controlled thorough QT study. $\mathrm{Br}$ $J$ Clin Pharmacol 2012;73:203-9.

41 Cheng E. Efficacy of prucalopride in the treatment of chronic constipation: a systematic review and meta-analysis of randomized controlled trials. Clin Gastroenterol Hepatol 2012;10:329-30.

42 Shin A, Camilleri M, Kolar G, et al. Systematic review with metaanalysis: highly selective 5-HT4 agonists (prucalopride, velusetrag or naronapride) in chronic constipation. Aliment Pharmacol Ther 2014;39:239-53.

43 Nelson AD, Camilleri M, Chirapongsathorn S, et al. Comparison of efficacy of pharmacological treatments for chronic idiopathic constipation: a systematic review and network meta-analysis. Gut 2017;66:1611-22.

44 Sajid MS, Hebbar M, Baig MK, et al. Use of prucalopride for chronic constipation: a systematic review and meta-analysis of published randomized, controlled trials. J Neurogastroenterol Motil 2016;22:412-22. 